\title{
BIOGRAFÍA \\ Alexander von Frantzius, notable pionero de nuestras ciencias naturales
}

\begin{abstract}
Alexander von Frantzius, notable pioneer of our natural sciences
\end{abstract}
\section{Luko Hilje ${ }^{1}$}

\section{Introducción}

Quienes nos hemos involucrado en el estudio de la historia de las ciencias naturales, a menudo nos encontramos con el serio obstáculo de que, con excepción de las publicaciones de un determinado científico, es poco lo que se conoce sobre ciertos personajes históricos cuyos aportes fueron realmente significativos para el desarrollo de la ciencia.

Este es el caso del médico y naturalista alemán Alexander von Frantzius, sobre quien hasta hace poco se contaba con apenas una breve semblanza (Tristán, 1907), con escasa información sobre su vida privada y profesional; dicha reseña se basa en un recuento biográfico preparado por Louis Hahn (Dechambre, 1880), al cual Tristán agregó algunos datos valiosos sobre los aportes científicos de von Frantzius para Costa Rica. Asimismo, aunque en años recientes apareció una biografía sobre este científico en la enciclopedia electrónica Wikipedia, esta es muy breve, además de que la versión en alemán contiene algunas inexactitudes.

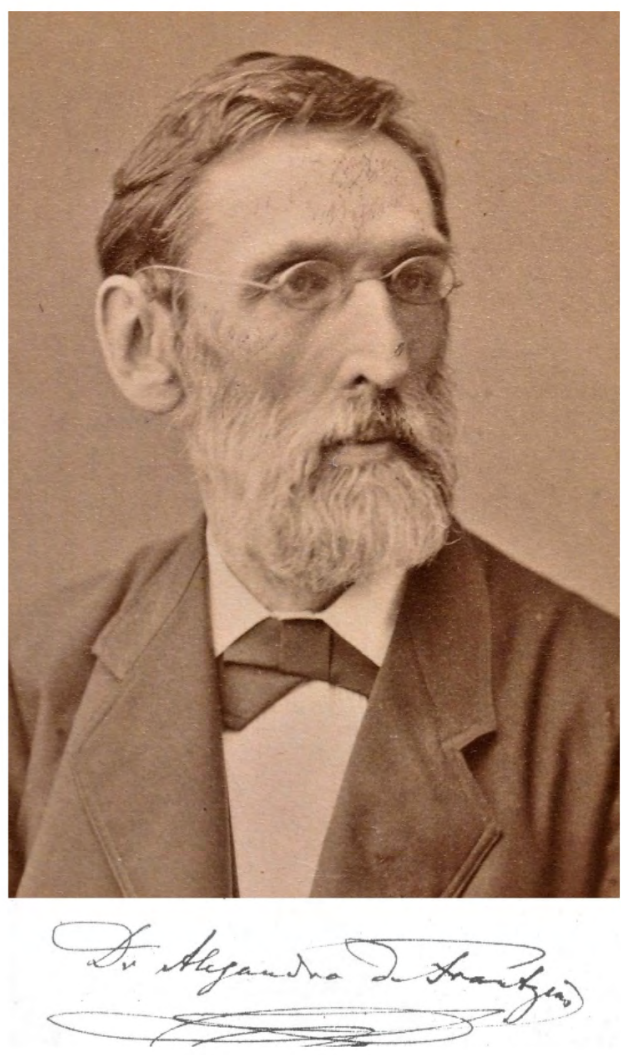

Sin embargo, por fortuna, durante la escritura de un libro sobre los naturalistas alemanes que exploraron Costa Rica en el siglo XIX (Hilje, 2013), una búsqueda en Internet nos permitió detectar la existencia de varias cartas remitidas por von Frantzius a su entrañable amigo Rudolf Virchow,

1 Profesor Emérito. Centro Agronómico Tropical de Investigación y Enseñanza (CATIE). Turrialba, Costa Rica. luko@ice.co.cr

\begin{tabular}{|c|c|c|c|c|c|}
\hline 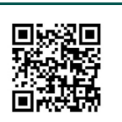 & (c) (1) () () & $\bigotimes_{\text {Aмmigturs }}$ & $\frac{O \mathscr{O} 6}{20}$ & 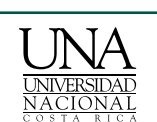 & 340 \\
\hline
\end{tabular}




\section{Revista de CIENCIAS AMBIENTALES Tropical Journal of Environmental Sciences}

Revista de Ciencias Ambientales (Trop J Environ Sci) e-ISSN: 2215-3896

(Julio-Diciembre, 2021) . Vol 55(2): 340-350 DOI: https://doi.org/10.15359/rca.55-2.17

Open Access: www.revistas.una.ac.cr/ambientales e-mail: revista.ambientales@una.ac.cr

Hilje L.

recopiladas por Andrée (1976). Fue gracias al acceso a dichas cartas, un breve obituario escrito por el propio Virchow y demás información proveniente de diversas fuentes, mediante lo cual se pudo establecer una trama de hechos y relaciones profesionales, de suma importancia para reconstruir y entender la evolución de von Frantzius como médico y científico, al igual que de su interés por el trópico americano. Aunque toda esa información aparece en Hilje (2013), el formato de dicho libro - una obra conceptual, más que biográfica - dificulta dar seguimiento a este personaje histórico como persona. Ello justifica la presente biografía, la cual pretende ser una síntesis de lo aparecido en dicho libro, además de enfatizar sobre sus aportes relacionados con la conservación de los recursos naturales.

\section{Su infancia y juventud}

Hace exactamente 200 años, cuando a mediados de 1821 en América Central soplaban vientos libertarios - que culminarían con la independencia de Guatemala, Honduras, El Salvador, Nicaragua y Costa Rica, el 15 de setiembre de 1821-, en la lejana Europa venía al mundo un niño a quien el destino enlazaría con Costa Rica de manera indisoluble.

En efecto, frente al mar Báltico, en el puerto de Danzig —actual Gdansk, Polonia-, el 10 de junio, el hogar formado por Friedrich Wilhelm von Frantzius Gorges y Adele Elisabeth Ritt Guise se regocijaba con el nacimiento del tercer miembro de la prole; antecedido Wilhelm y Adele, al cual lo sucederían Arthur Johann, Evelin Charlotte y Marie Alexandrine. Ese niño recibiría el nombre de Alexander, bautizado el 14 de agosto en la iglesia de Sankt Trinitatis.

Ya de joven, un hecho marcaría su futuro profesional: la presencia en Danzig del médico, zoólogo y fisiólogo, Carl Theodor Ernst von Siebold, quien años después sería profesor en las universidades de Erlangen, Friburgo, Breslau y Munich. Con apenas 13 años de edad, su interacción con el mentor von Siebold, fue de suma importancia para el joven, a quien el médico invitaba a sus excursiones zoológicas.

En 1842, al concluir la secundaria, Alexander se matriculó en la Universidad de Heidelberg para cursar la carrera de medicina, donde tuvo otro importante mentor, el anatomista y antropólogo, Alexander Ecker. Permaneció casi tres años ahí; en 1844 cursa un semestre en la Universidad de Erlangen, donde por entonces ejercía como docente su viejo maestro von Siebold. Posteriormente, por un breve período estudió en la Universidad de Halle y después se reencontraría con el itinerante von Siebold en la Universidad de Friburgo. Tanta inestabilidad obedecía a que, aunque deseaba ser médico, lo cautivaba la biología como disciplina científica; de hecho, influenciado por von Siebold, su primer interés fueron las gregarinas, organismos que parasitan a muchos invertebrados, con poca importancia médica.

Después de este periplo académico, ingresaría a la Universidad de Berlín donde se graduaría como médico el 5 de setiembre de 1846. Fue justamente en dicha institución donde entabló amistad con Rudolf Virchow, quien, aunque coetáneo de von Frantzius, se desempeñaba como profesor de anatomía patológica en La Charité, reputado hospital perteneciente a la Universidad

\begin{tabular}{|c|c|c|}
\hline 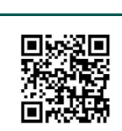 & (c) (i) (5) (2) & 341 \\
\hline
\end{tabular}




\section{Revista de CIENCIAS AMBIENTALES Tropical Journal of Environmental Sciences}

Revista de Ciencias Ambientales (Trop J Environ Sci) e-ISSN: 2215-3896

(Julio-Diciembre, 2021) . Vol 55(2): 340-350

DOI: https://doi.org/10.15359/rca.55-2.17

Open Access: www.revistas.una.ac.cr/ambientales e-mail: revista.ambientales@una.ac.cr

de Berlín. Brillante y acucioso investigador, años después Virchow sería nada menos que el proponente de la teoría celular, un concepto cardinal en la biología.

\section{Una vida profesional incierta}

Al parecer, ya graduado, von Frantzius no ejerció como médico, pues deseaba especializarse en el campo de la patología humana; sin embargo, no había oportunidades para, desde un puesto remunerado, combinar el aprendizaje con la investigación en esa disciplina. En su mente persistía la disyuntiva de ejercer como médico o dedicarse a la zoología. De hecho, en aquella época participó en una exploración zoológica a Trieste durante varios meses, organizada por sus admirados von Siebold y Ecker.

En determinado momento, a inicios de 1848, mientras permanecía en Viena en busca de oportunidades profesionales, manifestaba no sentirse bien consigo mismo. Reconocía que su labor científica había sido dispersa, sin dedicarse de lleno a ninguna disciplina, hecho que lo angustiaba. Dicha situación empeoró cuando terminó hospitalizado, víctima de una neumonía. Al enterarse de que, por esos días, Virchow estaba realizando una investigación en su campo, que daría lugar al extenso Informe de la epidemia de tifus en la Alta Silesia - que hasta hoy es considerado un clásico en la medicina social- se desplazó hacia esa región, para saludarlo y ayudarle; de hecho, Virchow lo menciona siete veces en su artículo. Lamentablemente, von Frantzius enfermó de tifus, causada por la bacteria Salmonella tiphy.

Cabe acotar que, por entonces, en varios países europeos había grandes movimientos populares contra el absolutismo monárquico, que alcanzarían el clímax el 18 de marzo, con el estallido de la Revolución de 1848, la cual duraría más de un año. Así, de regreso de Alta Silesia, tanto Virchow como von Frantzius se involucraron en las revueltas callejeras, a tal punto de ayudar en la construcción de barricadas en las calles de Berlín, en contra de los ataques del ejército. Así ocurrió con numerosos intelectuales y científicos de fuste.

Esto le costó el puesto a Virchow, y a von Frantzius terminó por complicarle la búsqueda de empleo, pues era calificado de sedicioso. Fue entonces cuando su amigo le recomendó que procurara conseguir una plaza como auxiliar de cátedra en zoología en la Universidad de Breslau. En esos días, mientras esperaba una oportunidad de trabajo, hubo una epidemia de cólera morbus en la ciudad — como parte de la segunda pandemia mundial de esta enfermedad - por lo que a inicios de 1849 le correspondió efectuar numerosas autopsias en el hospital de Breslau.

Tras muchos avatares, su situación laboral empezó a mejorar y, finalmente, se le abrieron las puertas de la Universidad de Breslau. En aquel momento alternó con investigadores como el fisiólogo y patólogo Jan Evangelista Purkinje, el fisiólogo y laringólogo Johann Czermak, el patólogo Friedrich Theodor von Frerichs, el químico Robert Bunsen y el físico Gustav Kirchhoff, famosos hasta hoy en sus respectivos campos. Mientras tanto, emprendió investigaciones por cuenta propia, tanto en el campo médico como en el zoológico.

Sin embargo, pronto solicitó un permiso para efectuar visitas a varias universidades europeas, así como para recibir un tratamiento especial en Italia, pues sus problemas de salud

\begin{tabular}{|c|c|c|}
\hline 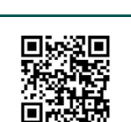 & (c) (i) () (2) (2) & 342 \\
\hline
\end{tabular}




\section{Revista de CIENCIAS AMBIENTALES Tropical Journal of Environmental Sciences}

Revista de Ciencias Ambientales (Trop J Environ Sci) e-ISSN: 2215-3896

(Julio-Diciembre, 2021) . Vol 55(2): 340-350 DOI: https://doi.org/10.15359/rca.55-2.17 Open Access: www.revistas.una.ac.cr/ambientales e-mail: revista.ambientales@una.ac.cr

Hilje L.

continuaban, ahora con frecuentes ataques de asma. Al retornar, las condiciones de trabajo no le eran muy favorables, ya que tuvo, además, conflictos con su gran mentor von Siebold. Pensó en renunciar, pero se quedaría sin salario y sin algunos instrumentos que le eran útiles para sus investigaciones. Por tanto, decidió permanecer ahí y mantenerse publicando artículos científicos, aunque de corta extensión y muy dispersos, tanto en medicina como en zoología.

En efecto, los artículos publicados fueron: Observaciones ulteriores sobre las gregarinas (1848); Aportes a la historia del desarrollo del sistema nervioso periférico (1851); Acerca de una especie de ácaro residente en la cavidad corporal del abejorro maderero (1851); Acerca de la metamorfosis en el reino animal, el cambio de generaciones y la heterogenia (1852); Acerca de las crías de Cephea (1852); Aportes a la fauna de coleópteros de Prusia (1854); y Restos fósiles de Anthracotherium minimum y una especie de antílope de Dalmacia (1854). Además, en 1853 publicó una traducción al alemán del libro Acerca de las partes de los animales, de Aristóteles. Nótese que algunos vieron la luz cuando él ya vivía en Costa Rica.

En realidad, von Frantzius continuaba atormentado, presa de su indecisión por uno u otro campo, al punto de que, en 1852, recién cumplidos los 31 años de edad, le expresaba a Virchow que se avergonzaba de no haber logrado hacer nada de fondo, todavía.

\section{El trópico: Una oportunidad impensada}

No hay evidencias de que von Frantzius alguna vez mostrara interés por explorar la naturaleza tropical, aunque de seguro había leído la emblemática obra Viaje a las regiones equinocciales del Nuevo Continente, escrita en 30 volúmenes por el célebre naturalista Alexander von Humboldt, tras recorrer por cinco años - entre 1799 y 1804- Venezuela, Colombia, Ecuador, Perú, Cuba y México.

Sin embargo, a mediados de 1851, de manera inesperada, conoció en Breslau a Franz Hugo Hesse, político que era uno de los líderes de la Sociedad Berlinesa de Colonización Agrícola para Centroamérica. Esta entidad público-privada representaba una especie de válvula de escape para la tensión social y política derivada de la Revolución de 1848 y pretendía establecer colonias de alemanes en el istmo centroamericano.

En realidad, al analizar en detalle la documentación referida al funcionamiento de dicha Sociedad (Hilje, 2020), se percibe que no había intenciones de realizar exploraciones de las riquezas naturales de Centroamérica, pero Hesse le ofreció a von Frantzius una plaza de naturalista. No obstante, como su salario sería cubierto por el Estado, debía contar con la aprobación de Humboldt quien, después de residir 23 años en París, había sido repatriado y fungía como consejero del rey de Prusia. Por tanto, von Frantzius viajó a Berlín y se reunió con él, quien frisaba los 82 años. Al parecer, le causó una buena impresión, pero después le comunicaron que para ese año ya no habría fondos.

Aunque fallido, este intento le abrió a von Frantzius la expectativa de estudiar la naturaleza de Centroamérica, la cual, en sus propias palabras, percibía como una región con gran potencial comercial y prácticamente inexplorada en términos biológicos, así como con un clima cálido,

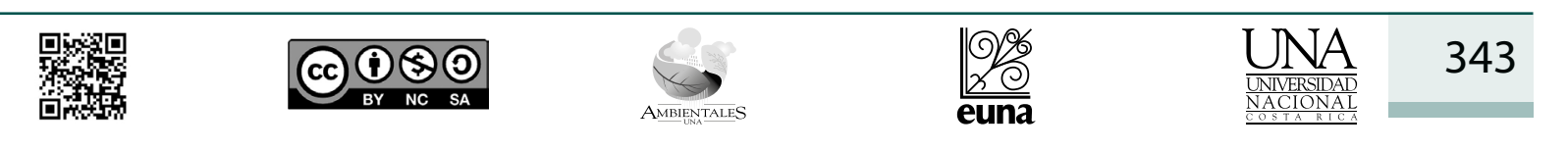




\section{Revista de CIENCIAS AMBIENTALES Tropical Journal of Environmental Sciences}

Revista de Ciencias Ambientales (Trop J Environ Sci) e-ISSN: 2215-3896

(Julio-Diciembre, 2021) . Vol 55(2): 340-350 DOI: https://doi.org/10.15359/rca.55-2.17

Open Access: www.revistas.una.ac.cr/ambientales e-mail: revista.ambientales@una.ac.cr

apto para paliar el asma que lo aquejaba. Para su fortuna, tiempo después aparecería una nueva oportunidad, pero por otra vía.

Es oportuno mencionar que a inicios de 1852 arribó a Costa Rica el abogado Fernando Streber, elegido como secretario de la Sociedad Berlinesa, en un proyecto de colonización de Angostura, Turrialba (Hilje, 2020). Por una grata casualidad, durante la insurrección de 1848, este había conocido en Berlín al médico y naturalista Karl Hoffmann, quien había sido compañero de estudios de von Frantzius en Berlín y, en algún momento, fue el que lo invitó a mudarse a Costa Rica. Sin duda, era una oferta tentadora, dada la difícil situación política y social que aún se vivía en Alemania, más el auspicioso futuro de la colonia alemana en Costa Rica, asociada con la construcción de un camino hacia Puerto Limón, que facilitaría la comunicación y el comercio con Europa. Además, había un vivo interés de Costa Rica y Nicaragua por construir un canal interoceánico binacional, aprovechando la ruta acuática natural del río San Juan y el lago de Nicaragua.

Cabe acotar que, en contraste con von Frantzius, cuyas investigaciones estaban restringidas a un laboratorio o una oficina, Hoffmann tenía experiencia de campo como naturalista, pues había recolectado plantas para la obra Flora Prusiana, coordinada por Albert Gottfried Dietrich. Además, parece que desde entonces había cultivado buenas relaciones profesionales con taxónomos, tanto del Museo Botánico de Berlín como del Museo Real de Zoología en Berlín, lo que después favorecería la identificación de numerosos especímenes de plantas y animales enviados desde Costa Rica.

Aunque se ignoran los detalles de cómo se gestó la iniciativa, lo cierto es que Hoffmann y von Frantzius decidieron viajar con sus propios recursos, con la esperanza de conseguir empleo en Costa Rica. Para ello, portaban sendas cartas de recomendación, una de Humboldt dirigida al presidente de la República, Juan Rafael (Juanito) Mora Porras, y otra del botánico Nees von Esenbeck, presidente de la Academia Leopoldina, la actual Academia Alemana de Ciencias. Asimismo, Humboldt logró que dicho ente les donara algunos aparatos científicos y, poco antes de partir ellos, con el título Investigación de Costa Rica, la famosa revista Bonplandia destinó completa su primera página a informar sobre esta expedición, que no tendría límite de tiempo.

\section{En Costa Rica}

El 24 de octubre de 1853, acompañados por sus esposas, von Frantzius y Hoffmann zarpaban de Bremen en el bergantín Antoinette; al parecer, la esposa del primero se llamaba Anna Fickeschen. En dicho navío viajaban unos cien alemanes, un tercio de los cuales venía para la futura colonia en Angostura. Tras navegar por casi dos meses, la nave atracó en San Juan del Norte (Greytown), en el Caribe nicaragüense. Cabe destacar que con ellos venía Julián Carmiol, un hábil maestro-jardinero y naturalista que traía consigo a su segunda esposa y a cuatro niños de su primer matrimonio.

Después de un complicado viaje por la trocha que atravesaba las densas y muy lluviosas selvas de Sarapiquí, llegaron a San José a inicios de enero de 1854. Lo más urgente para ellos era

\begin{tabular}{|c|c|c|}
\hline 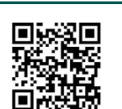 & (c) (1) (1) (2) & 344 \\
\hline
\end{tabular}




\section{Revista de CIENCIAS AMBIENTALES Tropical Journal of Environmental Sciences}

Revista de Ciencias Ambientales (Trop J Environ Sci) e-ISSN: 2215-3896

(Julio-Diciembre, 2021) . Vol 55(2): 340-350 DOI: https://doi.org/10.15359/rca.55-2.17

Open Access: www.revistas.una.ac.cr/ambientales e-mail: revista.ambientales@una.ac.cr

Hilje L.

conseguir un empleo. En realidad, a pesar de no poder comunicarse en español, ellos aspiraban a ejercer la docencia en la Universidad de Santo Tomás y dedicar el tiempo libre a sus exploraciones. Sin embargo, esto no era factible, pues no había entonces una carrera de medicina ni tampoco de farmacia en tal universidad.

Por tanto, para ganarse la vida, debieron dedicarse al ejercicio de su profesión desde sus boticas-consultorios. Hoffmann instaló la suya al costado sur del actual Parque Central, pero von Frantzius pronto se percató de que el clima de la capital no le contrarrestaría su padecimiento de asma. Eso lo llevó a establecerse en la muy cálida Alajuela. En realidad, fue muy afortunado, pues tres meses después el propio don Juanito lo nombró médico de pueblo, una especie de médico comunitario, cuyo salario era bastante alto. Además, como él provenía de una familia con cierta holgura económica, con sus ahorros pudo comprar una amplia casa esquinera, una cuadra al oeste del actual Parque Central, donde por muchos años ha estado el Almacén Llobet; asimismo, adquirió dos amplias propiedades en la periferia de la ciudad.

Ahora bien, en contraste con Hoffmann, quien en 1855 escaló los volcanes Irazú y Poás, y de manera incesante recolectaba tanto plantas como animales - invertebrados y vertebradosque enviaba a identificar en los respectivos museos en Berlín, von Frantzius se había limitado - quizás por su enfermedad-a determinar el patrón anual térmico de la ciudad de Alajuela.

Para mala fortuna, no habían transcurrido dos años desde su llegada cuando surgió el peligro de una invasión del ejército filibustero comandado por el esclavista William Walker; este estaba financiado por poderosos personajes y sectores de los estados sureños de los EE.UU., que pretendían anexarse el territorio centroamericano. Cuando la amenaza se tornó inminente, en marzo de 1856 don Juanito convocó al pueblo a las armas, por lo que recibió el apoyo de los alemanes residentes en San José y entonces nombró a Hoffmann como Cirujano Mayor del Ejército Expedicionario, lo que lo obligó a desplazarse a los frentes de batalla en Guanacaste y Nicaragua. Aunque von Frantzius no lo acompañó, intervino de manera oportuna, al viajar hasta La Virgen en Sarapiquí, para operar y salvarle el brazo al general Florentino Alfaro Zamora, herido el 10 de abril en la batalla de Sardinal; además, aunque no hubo necesidad de utilizarlo, el gobierno le solicitó establecer un hospital de campaña en Alajuela.

Como consecuencia de la batalla del 11 de abril en Rivas, Nicaragua, ingresó a Costa Rica el bacilo del cólera morbus (Vibrio cholerae), el cual, poco después, aniquilaría cerca del $10 \%$ de nuestra población. Enfrentar esta devastadora epidemia desgastó la salud de Hoffmann en pocos meses. Y fue así como, tras padecer una afección crónica y degenerativa, fallecería tres años después, con apenas 35 años de edad.

\section{Von Frantzius como investigador}

A fines de 1857, von Frantzius se mudó a San José, donde a lo largo de los años viviría en diferentes puntos. Sin embargo, su último sitio de residencia fue una amplia casa (Figura 1) que después pertenecería al célebre educador Mauro Fernández Acuña; como una feliz coincidencia, su terreno ocupaba la esquina suroeste del actual predio del Museo Nacional.

\begin{tabular}{|c|c|c|}
\hline 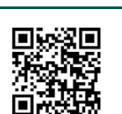 & (c) (1) () (2) & 345 \\
\hline
\end{tabular}




\section{Revista de CIENCIAS AMBIENTALES Tropical Journal of Environmental Sciences}

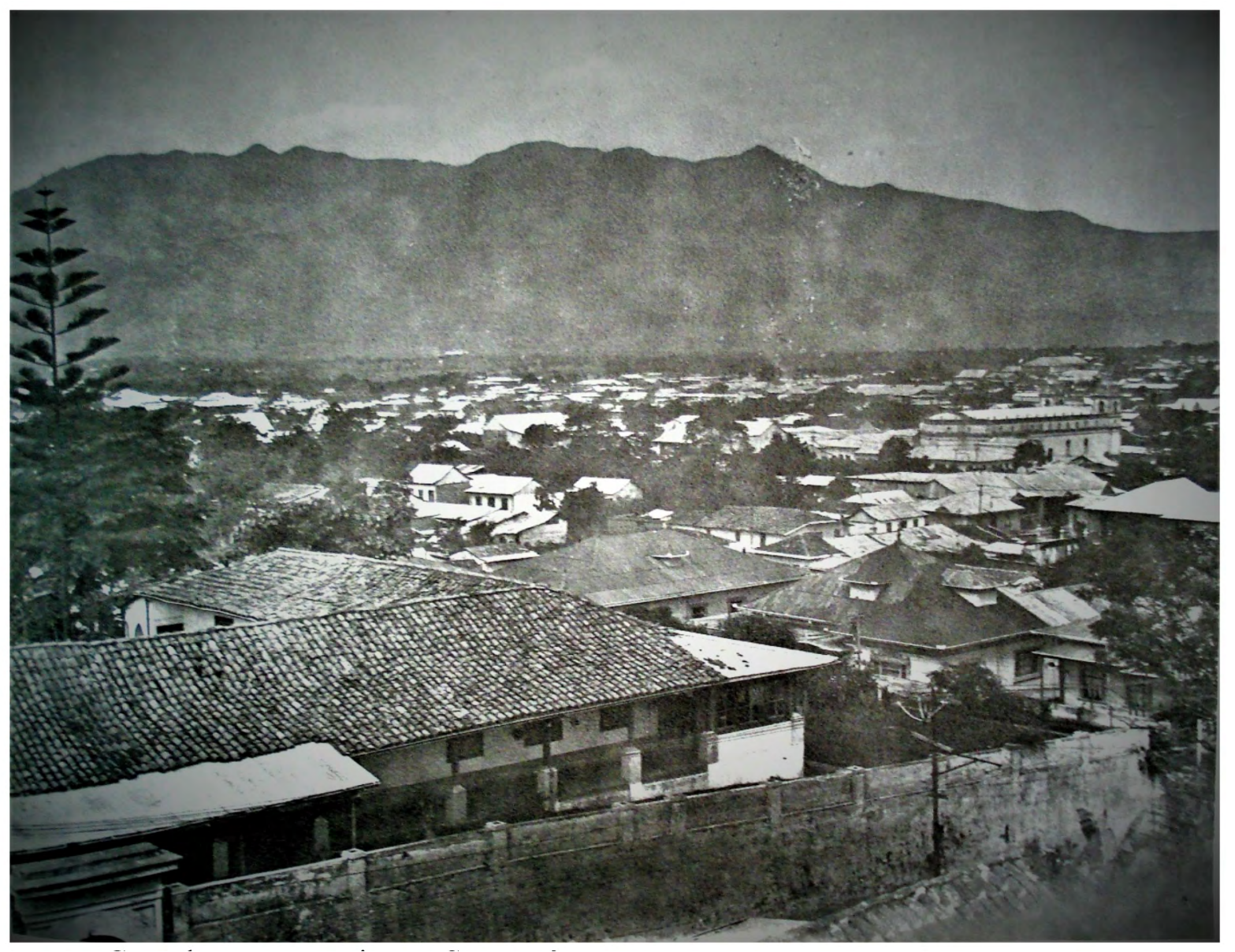

Figura 1. Casa de von Frantzius en San José.

Figure 1. Von Frantzius house in San José.

Cabe señalar que cuando von Frantzius se trasladó a la capital, ya Hoffmann estaba muy enfermo y eso le dificultaba emprender giras al campo, e incluso ejercer su profesión. Ello impidió que efectuaran alguna exploración juntos. Sin embargo, consciente de que se acercaba su final, Hoffmann depositó en manos de su amigo las colecciones que tenía, así como las listas de especies de aves y mamíferos, ya identificadas en Berlín por Jean Louis Cabanis y Wilhelm Peters, respectivamente.

Es oportuno acotar que, como el propio von Frantzius lo reconocía reiteradamente en sus cartas, sus ocupaciones de médico y su maltrecha salud le impedían efectuar excursiones a lugares distantes. Sin embargo, con gran acierto, hizo que algunos jóvenes que contrataba como dependientes en su botica - entre los que destacaron José Cástulo Zeledón Porras y Juan José Cooper Sandoval - aprendieran las artes de la recolección y la taxidermia, de modo que ellos se encargaban de tales tareas, mientras él enviaba los especímenes, inicialmente a Berlín y después

\begin{tabular}{|c|c|c|}
\hline 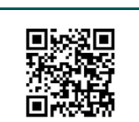 & (c) (i) @) (2) & 346 \\
\hline
\end{tabular}




\section{Revista de CIENCIAS AMBIENTALES Tropical Journal of Environmental Sciences}

Revista de Ciencias Ambientales (Trop J Environ Sci) e-ISSN: 2215-3896

(Julio-Diciembre, 2021) . Vol 55(2): 340-350 DOI: https://doi.org/10.15359/rca.55-2.17 Open Access: www.revistas.una.ac.cr/ambientales e-mail: revista.ambientales@una.ac.cr

Hilje L.

al Instituto Smithsoniano, en Washington, donde lo apoyaban los expertos Spencer F. Baird y George N. Lawrence.

Fue así como, en una copiosa cosecha en beneficio de Costa Rica y de la ciencia, en los 14 años que residió en nuestro país - partió en 1868, poco después de la muerte de su esposa-, pudo acopiar la información necesaria para publicar 18 amplios y valiosos artículos que cubren disciplinas y tópicos muy diversos.

Por ejemplo, en el campo zoológico sobresalen los artículos Distribución geográfica de las aves costarricenses, su modo de vivir y costumbres (1869) y Los mamiferos de Costa Rica; contribución para el conocimiento de la extensión geográfica de los mamíferos de América (1869), los cuales, en realidad, son catálogos.

Por su parte, en aspectos geográficos figuran los textos La ribera derecha del río San Juan; hasta ahora una parte casi completamente desconocida de Costa Rica (1862), Ensayo de una fundamentación científica de las condiciones climatológicas de Centro América (1868), Cartografía de Costa Rica (1869) y La parte sureste de la República de Costa Rica (1869). A ellos se suman dos de carácter geológico: Aporte al conocimiento de los volcanes de Costa Rica (1861) y Las fuentes termominerales en Costa Rica (1862).

En cuanto a artículos de contenido etnográfico o antropológico, escribió El antiguo convento de la misión de Orosi en Cartago de Costa Rica (1860) y Sobre los aborígenes de Costa Rica (1870). Asimismo, tradujo al alemán, con abundantes anotaciones, el Informe oficial del Licenciado Diego García de Palacio al Rey de España sobre las provincias centroamericanas de San Salvador y Honduras el año de 1576 (1873).

Además, en el campo histórico propiamente dicho, publicó El ferrocarril de Costa Rica como ruta de tráfico interoceánico, y su importancia para Costa Rica (1868) y Acerca del verdadero sitio de las ricas minas de Tisingal y Estrella, buscadas sin resultado en Costa Rica (1869).

Finalmente, como la medicina no podía estar ausente de sus pesquisas, escribió los artículos Sobre la dispersión de la malaria en Costa Rica (1868), Sobre la existencia de larvas de moscas en las cavidades nasales de habitantes tropicales, los cuales sufren de ocena (1868) y Heridas ponzoñosas en animales y seres humanos a través de la picadura de la araña excavadora existente en Costa Rica (Mygale) (1869).

Cabe acotar que en Hilje (2013) se presenta un análisis del contexto en que apareció cada uno de esos artículos, al igual que algunos comentarios sobre su contenido.

Es importante resaltar que, de manera simbólica y en reconocimiento a su rico legado científico, portan su apellido varias especies de aves (Figura 2), así como un cono localizado detrás del cráter del volcán Poás y un cerro al sur de Costa Rica. Asimismo, aunque nunca mostró interés por la botánica, años después se le honró en los nombres del rabo de gato (Stachytarpheta frantzii) y el tacaco (Sechium tacaco), el cual por un tiempo se denominó Frantzia tacaco.

\begin{tabular}{|c|c|c|c|c|}
\hline & & & (ब) (1) \\
\hline
\end{tabular}




\section{Revista de CIENCIAS AMBIENTALES Tropical Journal of Environmental Sciences}

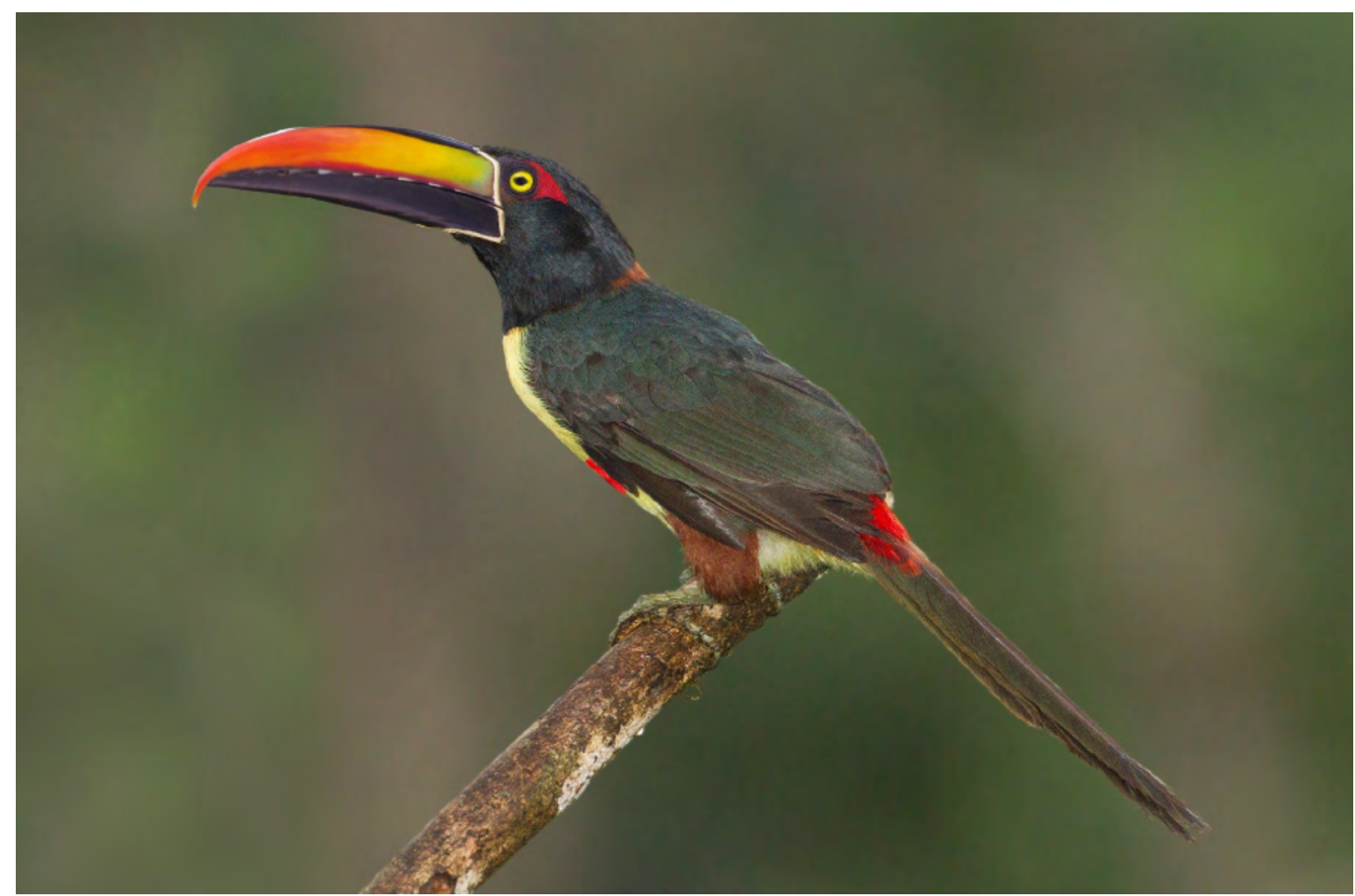

Figura 2. El tucán Pteroglossus frantzii, conocido como "cusingo".

Figure 2. The toucan Pteroglossus frantzii, known as "cusingo".

\section{Epílogo}

Antes del arribo de von Frantzius, Hoffmann y Carmiol — recolector de plantas y animales, más que investigador-, la biodiversidad de Costa Rica permanecía casi desconocida. Los únicos que la habían explorado eran dos naturalistas itinerantes, el austríaco Emmanuel Ritter von Friedrichsthal (1843) y el polaco Josef von Warszewicz (1848), así como uno residente, el danés Anders S. Oersted, que vivió por año y medio (1846-1848) en el país. Por tanto, la estadía de estos tres alemanes residentes era muy promisoria, hasta que el destino segó la vida del incansable y muy productivo Hoffmann, quien incluso había visualizado editar un libro colegiado, Flora y fauna de Costa Rica, escrito por él, von Frantzius y varios taxónomos alemanes.

Aunque, lamentablemente, von Frantzius no se interesó por las plantas ni por otros grupos animales, por fortuna sus catálogos de aves y mamíferos tuvieron como punto de partida la información que Hoffmann había acumulado, para, con el paso de los años, proceder a ampliarlo y profundizarlo, con la ayuda de sus jóvenes recolectores. Tan impresionante fue su labor, que en su catálogo de aves figuraban 517 de las 890 especies conocidas para Costa Rica en la

\begin{tabular}{|c|c|c|}
\hline 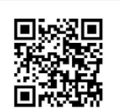 & (c) () (9) & 348 \\
\hline
\end{tabular}




\section{Revista de CIENCIAS AMBIENTALES Tropical Journal of Environmental Sciences}

Revista de Ciencias Ambientales (Trop J Environ Sci) e-ISSN: 2215-3896

(Julio-Diciembre, 2021) . Vol 55(2): 340-350 DOI: https://doi.org/10.15359/rca.55-2.17

Open Access: www.revistas.una.ac.cr/ambientales e-mail: revista.ambientales@una.ac.cr

actualidad —casi el $60 \%$-, con tan solo 15 años de recolección sistemática, cuando los pocos caminos de acceso a algunas zonas del país eran intransitables y algunas regiones eran realmente inaccesibles.

Sin embargo, además de los muy valiosos y originales aportes científicos en varios campos, a von Frantzius le corresponde el inmenso mérito de haber entendido y visualizado que, tras su partida, sus esfuerzos podrían desplomarse si no se les daba continuidad. Y fue por ello que se esmeró porque su talentoso pupilo José Cástulo Zeledón realizara una dilatada pasantía en el Instituto Smithsoniano, lo que con los años le permitiría convertirse en el primer ornitólogo y naturalista costarricense (Hilje, 2018) y, a su vez, ser una figura clave en la fundación del Museo Nacional, un ente de gran trascendencia en la institucionalización de nuestras ciencias naturales.

Hoy, cuando dos siglos después de su independencia a Costa Rica se le percibe como un país que a lo largo del tiempo ha sabido proteger sus recursos naturales y convertir el turismo ecológico - con un fuerte énfasis en la observación de aves - en una importante fuente de divisas, es justo reconocer y honrar los aportes de numerosos naturalistas que, como von Frantzius, supieron avizorar y abrir promisorias sendas, guiados por ese íntimo y recóndito impulso de explorar y conocer, que solo ellos pueden comprender a plenitud.

Cinco semanas después de alcanzar los 56 años de edad - cuando aún tenía tanto que aportar, sobre todo en el campo de la antropología, a la que dedicó sus últimos años-, ya en el lecho al que lo condujo la implacable asma, aquel 18 de julio de 1877, poco antes de expirar, quizás von Frantzius evocó con nostalgia su prolongada estadía en el trópico mesoamericano. Eso sí, de seguro que, en tal estado de postración, no pudo sopesar cuán importante y perdurable sería su legado para nuestras ciencias naturales.

No obstante, a casi siglo y medio de ese infausto día, esta breve biografía patentiza cuán fecunda y robusta fue su obra, con el propósito de que sirva de modelo e inspiración, sobre todo a los jóvenes dedicados al estudio y conservación de nuestros recursos naturales.

\section{8. Ética y conflicto de intereses}

La persona autora declara que han cumplido totalmente todos los requisitos éticos y legales pertinentes, tanto durante el estudio como en la producción del manuscrito; que no hay conflicto de interés de ningún tipo; y que están totalmente de acuerdo con la versión final editada del artículo.

\section{Agradecimientos}

A quienes aportaron información sobre von Frantzius para mi libro, y en particular a Silvia Kruse Quirós, traductora de numerosas cartas. A Tad Bennicoff y Heidi Stover (Smithsonian Institution Archives) y Yamil Sáenz, por facilitarme las fotos de von Frantzius y el tucán, respectivamente.

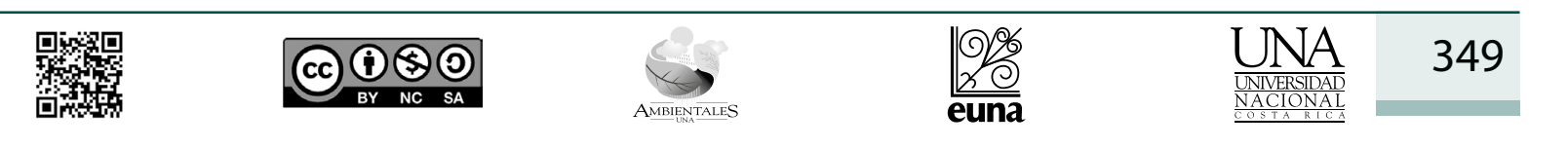




\section{Revista de CIENCIAS AMBIENTALES Tropical Journal of Environmental Sciences}

Revista de Ciencias Ambientales (Trop J Environ Sci)
e-ISSN: 2215-3896
(Julio-Diciembre, 2021) . Vol 55(2): 340-350
DOI: https://doi.org/10.15359/rca.55-2.17
Open Access: www.revistas.una.ac.cr/ambientales
e-mail: revista.ambientales@una.ac.cr

Hilje L.

\section{Referencias}

Andrée, C. (Ed.). (1976). Rudolf Virchow als Prähistoriker (Vol. II). Editorial Böhlau.

Dechambre, A. (1880). Dictionnaire encyclopédique des sciences médicales (Serie 4, Tomo 6). París.

Hilje, L. (2013). Trópico agreste; la huella de los naturalistas alemanes en la Costa Rica del siglo XIX. Editorial Tecnológica de Costa Rica.

Hilje, L. (2018). José Cástulo Zeledón, primer naturalista costarricense. Revista de Ciencias Ambientales, 52(1), 209-220. https://doi.org/10.15359/rca.52-1.12

Hilje, L. (2020). La bandera prusiana ondeó en Angostura. Instituto Costarricense de Electricidad. Tristán, J. F. (1907). Alejandro v. Frantzius. Páginas Ilustradas, 128, 2053-2056.

\begin{tabular}{|c|c|c|c|c|c|}
\hline 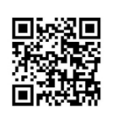 & (c) (1) (5) () & $\underset{\text { AMBENTALS }}{\leftrightarrow}$ & $\frac{O \%}{20}$ & $\frac{\text { UNA }}{\frac{\text { UNIIERSIDAD }}{\text { NASIONAL }}}$ & 350 \\
\hline
\end{tabular}

